\title{
Follow-up MRI study of prefrontal volumes in first- episode psychotic patients
}

\section{Citation}

Dickey, Chandlee C., Dean F. Salisbury, Almos I. Nagy, Yoshio Hirayasu, Chang Uk Lee, Robert W. McCarley, and Martha E. Shenton. 2004. "Follow-up MRI Study of Prefrontal Volumes in FirstEpisode Psychotic Patients." Schizophrenia Research 71 (2-3) (December): 349-351. doi:10.1016/ j.schres.2004.04.010.

\section{Published Version}

doi:10.1016/j.schres.2004.04.010

\section{Permanent link}

http://nrs.harvard.edu/urn-3:HUL.InstRepos:28559584

\section{Terms of Use}

This article was downloaded from Harvard University's DASH repository, and is made available under the terms and conditions applicable to Other Posted Material, as set forth at http:// nrs.harvard.edu/urn-3:HUL.InstRepos:dash.current.terms-of-use\#LAA

\section{Share Your Story}

The Harvard community has made this article openly available.

Please share how this access benefits you. Submit a story.

\section{Accessibility}




\title{
Follow-up MRI study of prefrontal volumes in first-episode psychotic patients
}

\author{
Chandlee C. Dickeya,b, Dean F. Salisbury ${ }^{a, c}$, Almos I. Nagya ${ }^{a}$ Yoshio Hirayasud, Chang Uk \\ Lee $^{e}$, Robert W. McCarleya,f, ${ }^{*}$, and Martha E. Shentona,f, ${ }^{,}$ \\ ${ }^{a}$ Clinical Neuroscience Division, Laboratory of Neuroscience, Department of Psychiatry (116A), VA \\ Boston Healthcare System, Brockton Division, and Harvard Medical School, 940 Belmont St., \\ Brockton, MA 02301, United States \\ bBrigham Behavioral Neurology Group, Brigham and Women's Hospital, Boston, MA, United States \\ 'Cognitive Neuroscience Laboratory, McLean Hospital, Belmont, MA, United States \\ dYokohama City University School of Medicine, Yokohama, Japan \\ eDepartment of Psychiatry, Catholic University Medical College, Seoul, South Korea \\ fSurgical Planning Laboratory, MRI Division, Brigham and Women's Hospital, Department of \\ Radiology, Harvard Medical School, Boston, MA, United States
}

\begin{abstract}
Structural MRI findings of abnormalities in the prefrontal cortex in schizophrenia and affective disorder have been inconsistent likely due to small, heterogeneous samples, the evaluation of prefrontal gray and white matter combined, and the fact that prefrontal cortex is typically not delineated into separate gyri (e.g., Shenton et al., 2001; Strakowski et al., 2002). We previously reported smaller prefrontal gray matter in first-episode schizophrenia relative to first-episode affective psychosis and controls (Hirayasu et al., 2001). One unresolved question in the literature is whether or not further volume reduction will be observed over time, the focus of this report.
\end{abstract}

\begin{abstract}
Prefrontal gray and white matter volumes were measured (see Fig. 1) in patients at the time of first hospitalization for schizophrenia ( $n=12,3$ females) or affective psychosis $(n=10,1$ female, 9 bipolar, 1 unipolar), and psychiatrically well subjects $(n=15,1$ female). Subjects were rescanned approximately 1.5 years later. Seven schizophrenia, six affective, and four comparison subjects were previously described solely at first scan (Hirayasu et al., 2001). Samples did not differ in age $(28.1 \pm 8.4 ; 22.9 \pm 2.8 ; 25.4 \pm 4.5 ; F(2,34)=2.2, p=0.12)$ or WAIS Information scores $(11.8 \pm 3.4 ; 12.2 \pm 3.1,11.8 \pm 2.0 ; F(2.32)=0.6, p=0.9)$, nor in parental socioeconomic status $(F(2.34)=2.32, p=0.11)$ or handedness $(F(2.33)=1.6, p=0.22)$. BPRS scores were higher in schizophrenics $(41.2 \pm 13.2)$ than affectives $(33.8 \pm 8.0)(F(1,20)=5.71$, $p=0.027$ ). Similar neuroleptics were prescribed for the patient groups (schizophrenics: 7 typical, 4 atypical, 1 none; affectives: 6 typical, 3 atypical, 1 none).
\end{abstract}

Relative volumes [i.e., absolute volumes divided by intracranial contents (ICC)] were used in the analyses. Repeated-measures ANOVA was performed with diagnosis as the between-

(C) 2004 Elsevier B.V. All rights reserved.

*Corresponding authors. Clinical Neuroscience Division, Laboratory of Neuroscience, Department of Psychiatry (116A), VA Boston Healthcare System, Brockton Division, and Harvard Medical School, 940 Belmont St., Brockton, MA 02301, United States. Tel.: +1 508 583 4500x1371 or x2473; fax: +1 508580 0894. robert_mccarley@hms.harvard.edu (R.W. McCarley), martha_shenton@hms.harvard.edu (M.E. Shenton). 
subjects factor and time and side as the within-subjects factors for gray and white matter separately.

Prefrontal gray matter at time 1 was significantly different among groups $(F 2,30=5.56$, $p=0.009$ ), with schizophrenics smaller than controls and affectives, who did not differ from each other. There was no interaction for group by time by side for prefrontal gray matter $(F 2,34=0.65, p=0.53)$. All groups showed larger gray matter on the left $(F 2,30=8.72, p=0.006)$.

White matter volumes did not differ among groups $(p>0.87)$, and all groups showed more white matter on the right $(F 1,30=39.20, p<0.001)$ and a reduction over time $(F 1,30=10.902$, $p=0.002)$, there was a trend for this effect to be larger on the right $(F 1,30=3.14, p=0.086)(\%$ change over time for right white matter: schizophrenics $2.8 \%$; affectives $6.5 \%$; controls $2.1 \%$ ). Neither removing the unipolar depression subject nor removing the females altered the results. There was no significant correlation between ROI volume change and medication dosage at time 1 for either patient group (Time 2 data came from out patients based on self-report and was for this reason not used).

These data suggest that prefrontal cortical gray matter is selectively smaller at first hospitalization for schizophrenia relative to affective psychosis and controls, but this volume difference did not change over the relatively short post-first hospitalization time examined. Small gray matter volumes may be due to reduced dendritic arborization or increased neural density in prefrontal cortex in schizophrenia (Benes et al., 1992; Selemon et al., 1998). White matter, which was not different among groups, showed a decline with time in all groups, possibly consistent with normal aging (Good et al., 2001, although Bartzokis et al., 2001).

Potential reasons for our not observing selective gray matter reductions point to several limitations of this study including the gender distribution, as females may have greater dorsolateral and orbitofrontal lobe involvement and males greater dorsomedial changes in schizophrenia (Gur et al., 2000); the use of large ROI, as sub-regions within the prefrontal cortex may change in volume at different rates (Gur et al., 1998; DeLisi et al., 1997); and lack of exact medication dosages and compliance histories during the intrascan interval cannot be ruled out as possible confounds. Although the sample size was small, the effect size was also small (Fig. 1) suggesting that even enlarging the sample would not result in a significant change in volume over time for either gray or white matter.

\section{References}

1. Bartzokis G, Beckson M, Lu PH, Nuechterlein KH, Edwards N, Mintz J. Age-related changes in frontal and temporal lobe volumes in men: a magnetic resonance imaging study. Arch. Gen. Psychiatry 2001;58(5):461-465. [PubMed: 11343525]

2. Benes FM, Sorensen I, Vincent SL, Bird ED, Sathi M. Increased density of glutamate-immunoreactive vertical processes in superficial laminae in cingulate cortex of schizophrenic brain. Cereb. Cortex 1992;2(6):503-512. [PubMed: 1282404]

3. DeLisi LE, Sakuma M, Tew W, Kushner M, Hoff AL, Grimson R. Schizophrenia as a chronic active brain process: a study of progressive brain structural change subsequent to the onset of schizophrenia. Psychiatry Res 1997;74(3):129-140. [PubMed: 9255858]

4. Good CD, Johnsrude IS, Ashburner J, Henson RN, Friston KJ, Frackowiak RS. A voxel-based morphometric study of ageing in 465 normal adult human brains. NeuroImage 2001;14(1 Pt 1):2136. [PubMed: 11525331]

5. Gur RE, Cowell P, Turetsky BI, Gallacher F, Cannon T, Bilker W, Gur RC. A follow-up magnetic resonance imaging study of schizophrenia. Relationship of neuroanatomical changes to clinical and neurobehavioral measures. Arch. Gen. Psychiatry 1998;55(2):145-152. [PubMed: 9477928] 
6. Gur RE, Cowell PE, Latshaw A, Turetsky BI, Grossman RI, Arnold SE, Bilker WB, Gur RC. Reduced dorsal and orbital prefrontal gray matter volumes in schizophrenia. Arch. Gen. Psychiatry 2000;57(8): 761-768. [PubMed: 10920464]

7. Hirayasu Y, Tanaka S, Shenton ME, Salisbury DF, DeSantis MA, Levitt JJ, Wible C, Yurgelun-Todd D, Kikinis R, Jolesz FA, McCarley RW. Prefrontal gray matter volume reduction in first episode schizophrenia. Cereb. Cortex 2001;11(4):374-381. [PubMed: 11278200]

8. Selemon LD, Rajkowska G, Goldman-Rakic PS. Elevated neuronal density in prefrontal area 46 in brains from schizophrenic patients: application of a three-dimensional, stereologic counting method. J. Comp. Neurol 1998;392(3):402-412. [PubMed: 9511926]

9. Shenton ME, Dickey CC, Frumin M, McCarley RW. A review of MRI findings in schizophrenia. Schizophr. Res 2001;49(1-2):1-52. [PubMed: 11343862]

10. Strakowski SM, Adler CM, DelBello MP. Volumetric MRI studies of mood disorders: do they distinguish unipolar and bipolar disorder? Bipolar Disord 2002;4(2):80-88. [PubMed: 12071513] 
a.

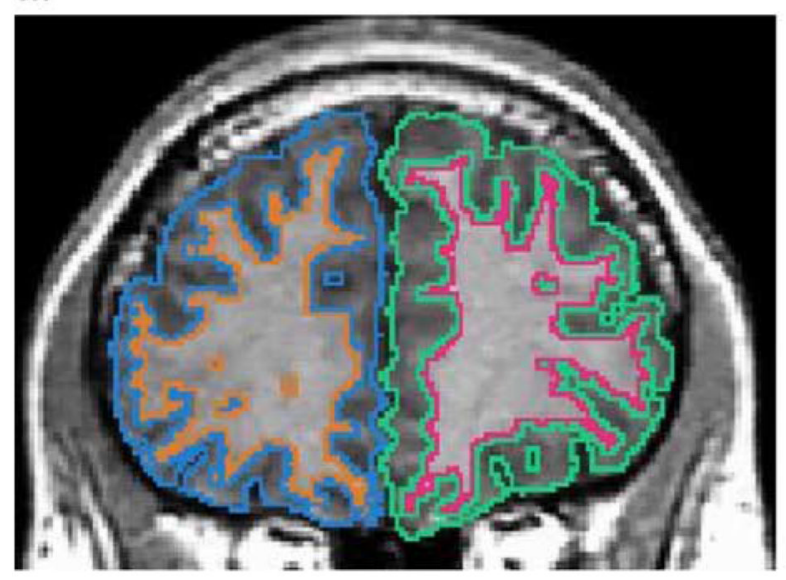

c.

b.
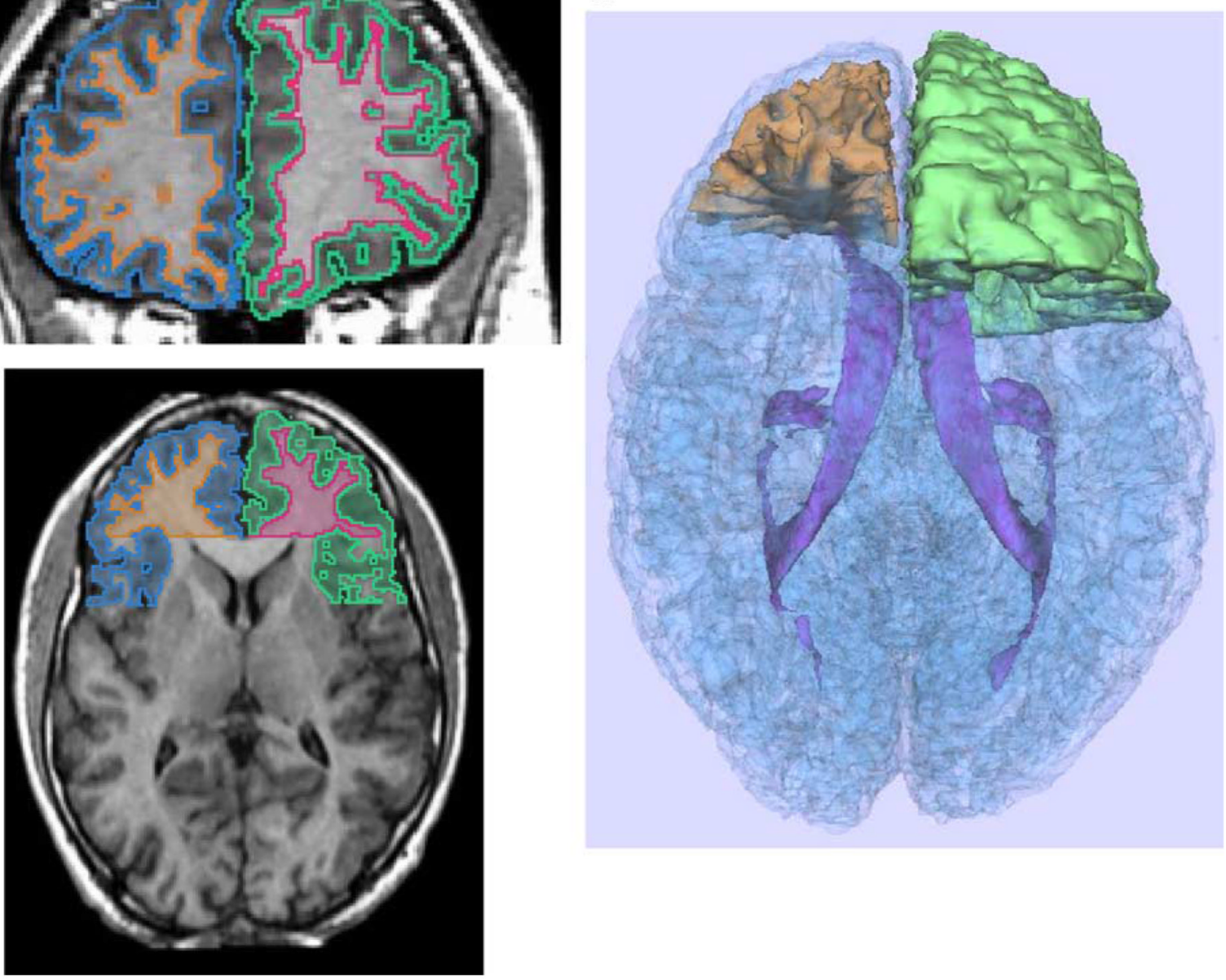

Fig. 1.

Prefrontal ROI definitions and volumes. (a) Coronal slice, (b) axial slice showing prefrontal gray and white matter, and (c) three. Three-dimensional reconstruction of the extent of gray and white matter boundaries. MR images were acquired with a 1.5-T scanner (GE Medical Systems, Milwaukee). Coronal SPGR images $1.5 \mathrm{~mm}$ thick were segmented into tissue class and subsequently realigned, reformatted, and resampled (isotropic voxels $0.9375 \mathrm{~mm}^{3}$ ) to ensure similar head alignment between time 1 and time 2. Minimal manual editing was performed by a single rater. Axial double-echo images $3 \mathrm{~mm}$ thick were used to determine the ICC. Measurement of gray matter began on the most anterior slice containing brain tissue. The five most anterior slices were considered to be solely gray matter, with the anterior boundary of the white matter commencing on the sixth slice. The posterior landmark for gray matter was the slice five slices anterior to the appearance of the temporal stem (the white matter tract connecting the temporal and frontal lobes) and for the white matter, the tip of the frontal horns. Right side of image is left side of brain. ANOVA revealed no significant differences in ICC volume among the three groups. Follow-up ICC volumes were smaller $(F 1,30=10.66$, $p=0.003$ ), however, the average difference was $0.58 \%$. ROI absolute volumes in $\mathrm{ml}$ given for time 1 for schizophrenic, affective, and comparison subjects respectively with standard deviations in parentheses, effect sizes given as partial eta squared are listed: left gray: 80.0 
(9.3), 86.0 (9.7), 88.7 (11.2); right gray: 79.3 (9.5), 84.6 (10.7), 87.1 (11.6) [for left and right gray matter over time $=0.037$, small effect]; left white: 28.3 (3.0), 28.8 (4.1), 30.0 (5.0); and right white $31.3(3.5) ; 32.2(6.2), 31.8$ (5.0) [for left and right white matter over time $=0.048$, small effect]; and time 2 left white 27.6 (2.8), 27.5 (3.8), 29.4 (4.9); and time 2 right white 30.2 (3.2), 29.8 (4.2), 31.1 (4.9). 